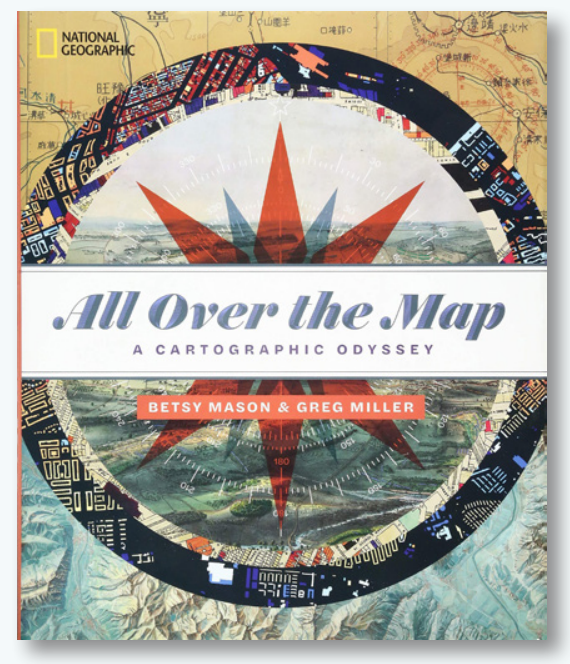

\title{
ALL OVER THE MAP: A CARTOGRAPHIC ODYSSEY
}

By Betsy Mason and Greg Miller

National Geographic, 2018

318 pages, about 300 maps and photographs

Hardcover: \$50.00, ISBN 978-1-4262-1972-6

Review by: Daniel “daan” Strebe, Mapthematics, LLC

One Might EXPect a book entitled All Over the Map to hop back and forth over time and thematic space, and this book does indeed do that. This lavishly illustrated, journalistic ramble bounces from topic to topic, dipping in here, tasting there, and spinning tales about the diverse selection of maps it visits. Do not expect depth or focus, but be prepared for entertaining surprises.

At twelve inches tall and ten wide, you are probably not going to be reading this book in bed, or on the bus. This large quarto volume justifies its size, however, with its many illustrations that are large, clear, and readable, despite frequently being much reduced from their original sizes. Where needed, which is often, the authors give detail excerpts with captions.

Like most National Geographic books, this one would be right at home on a sitting room coffee table-a collection of gorgeous maps to be thumbed through and admired. But there is no shortage of books filled with gorgeous maps, and All Over the Map is not distinguished by its eye candy alone. Tossing it on the table to look at now and then would be to squander its value. Yes, the maps are magnificent, but the texts are well written and informative, too. The authors are journalists, and it shows; they spent many years developing the content, and that shows, too. It shows even if you choose only to browse, sample, and taste your way through the book. You don't have to follow any particular order, but simply looking isn't enough.
Mason and Miller carve their tour up into nine chapters, each some thirty-odd pages long: "Waterways," "Cities," "Conflict and Crisis," "Landscapes," "Economies," "Science," "Human Experiences," "Worlds," and "Art and Imagination." Many, or most, of the maps might have been included under more than one of the categories, but for the most part their scheme works well enough.

Chapters open with a short thematic introduction, and then launch straight into the storytelling. Each chapter consists, on average, of nine sections relating to some topical aspect of the chapter theme. Many sections describe a single map, while others deal with collections of related maps. A few are about several maps from a single mapmaker. The heading for each section includes a statement about the maps it contains: the Creator (or the Source) and the year(s) the map(s) were Created-a span sometimes ranging to a century or more. The authors make good use of map comparisons to get their story across-for example, in the section on the maps portraying Boston's centuries-long land-building enterprise (70-73).

It would be impossible to give an overall flavor for All Over the Map-it consists of eighty-one independent, very different tales that simply cannot be characterized generally. At best I can confirm that they are, indeed, all over the map: from Jerry Gretzinger's giant, abstract, algorithmically evolving, fictional map thingy (282-285); to eighteenth-century Tōkaidō pilgrimage maps (218-221); to Henry Acland's exacting, but tragically wrong, 1856 maps 
of choleric miasma (180-183); to Jim Nieuhues's cartographic ski-slope artistry (139-141); and, yes, to a fly-over map of Westeros. (290-293)

Most of these stories describe, above all else, labors of love. It took decades of hard work to produce some of the maps you will read about, by people who refused be satisfied with the maps that had hitherto existed and how they had been done. You will read about Ferdinand Hasslerthe man entrusted by the US government with mapping the young country's coasts-and how he spent 36 years obsessively building and perfecting the US Coast Survey's mapping and surveying skills, only to die a year before it finally published its first map (42-43). You will read about the decades Marie Tharp spent methodically accruing evidence for plate tectonics, recognizing the emerging patterns in seafloor features long before her colleagues could bear to, culminating in a world bathymetric map so strikingly beautiful and startlingly persuasive that it is still widely used forty years later (184-189).

This book's design is dominated by the maps-there isn't a full page of text anywhere in the body of the volume-but that text is constantly engaging and laced with delightful facts. At least I found it delightful to learn that, for example, San Francisco's underground street car tracks pass through the buried hull of a nineteenth-century ship. Most of the delightful facts were new to me, even when the maps were not. If you don't delight in such facts, then perhaps this is not the book for you.

The physical quality of the book is high but not outstanding. Signatures of eight leaves are sewn and glued to a good quality binding. The paper is medium bright, medium weight, and fairly opaque with only a little showthrough. The illustrations are medium-glossy and in color unless the original image was not. The print quality is serviceable, but not the best, and the print smudges on pages 289 and 304 of my copy were a bit disappointing. The dust jacket is expensively produced with spot varnish overprinting, and is commensurately attractive.

I'm not sure what to make of the font choices in All Over the Map. The body text is a large $\mathrm{x}$-height sans serif-as are the image captions, albeit in a smaller size. The initial paragraph of each chapter, by contrast, uses a high-contrast serifed face that is close to, but not quite, Century Schoolbook-the same font used in italic form for the chapter and section titles. Maybe I'm just old-fashioned, but I find serifed body text more readable, and would have reversed the choices for lead and body-leaving the captions as they are. Print size is about typical for an illustrated book of this sort, but the book-weight typeface's lack of serifs leaves the "color" of the page a bit light. I did not find the typeface choices an impediment, but then again I was not reading for speed-your mileage may vary. In any case, there is no arguing with the overall pleasing aesthetics.

You are probably familiar with the National Geographic editing style-crisp, meticulous, approachable, and largely uncontroversial while listing toward environmental advocacy - and that is just what you will find here. The upper limit to cheeky prose seemed to be the remark that "Those seemingly random facts, in other words, may have had everything to do with the price of tea in China," (174) explaining why tea-drenched China had gotten such short shrift on an elaborate map of tea commerce and culture. The fact checking seems quite good; I only spotted two errors-one that had Mariner 4 arriving at Mars twenty years late to the party (251), and another I discuss below.

The authors, who also write the National Geographic All Over the Map blog (nationalgeographic.com/culture/allover-the-map), want you to know that they are not cartographers, but rather, journalists who like and write about maps. Be that as it may, whatever you want to call them and what they do-and however they see themselves and their own activities - they show a fair knack for nosing out and retelling interesting map-related facts, and display an obvious love for the maps, the stories, and the telling. Mason and Miller's love for maps shines through their work. By some measures, the authors have made their task easy - this book is not about any particular kind of map; it doesn't need, or care about, scholarly precision; it doesn't advance any particular thesis. They don't claim their showcased maps fairly sample space, or time, or culture, or their authors' gender identities, or political proclivities, or genre or, really, anything at all. Their criteria for inclusion was simply, "Is there a good story behind this map?" Without a doubt, each of the maps comes with a good story-but that's only part of the story, isn't it? It is obvious that the duo invested an immense amount of time and effort researching these stories, but I also infer that they lived and breathed maps for years. They would have had to, in order to find themselves in the right places at the right times to recognize that there was a story to research, and that the story could be compelling. 
The authors have a clear fondness for the underdog, as you can see in the stories about Arnold Colom (32-35), Pierre Charles L'Enfant (51-55), or even, again, Marie Tharp (184-189). Social justice in various forms crops up many times, for example in discussions of San Francisco's maps of moral corruption in Chinatown (214-217), James Cowles Prichard's progressive ethnographic maps of Africa (224-227), or Ebenezer Howard's utopian city designs (289-299). You will also find a good dose of present bias - a surprising number of the maps were produced in just the past few years. National Geographic has long understood that finding the broadest audience means telling topical stories. That is particularly important in a periodical, but it applies to books as well-most of a book's earnings come in the first year of sales. In the same vein, maps of the United States or by American authors are strongly represented. Anyone in the publishing business will tell you that it is just good business to reflect your audiences' interests, and your audience is usually most interested in themselves.

The book might be guilty, too, of a little National Geographic puffery. On the one hand, National Geographic has been on the scene for so long, and with such high standards, that they definitely deserve more than one inclusion, but do they deserve the five maps they have here? That is hard to say, but it doesn't much bother me. Still, in a text where most opinions are given cautiously, it's curious that the caption on the trophy map in the Introduction so matter-of-factly claims that "the artistry of the hand-drawn relief on this map of Mt. Everest, published as a supplement to the November, 1988 issue of National Geographic, has yet to be rivaled" (8). Is the claim defensible? Absolutely. Is it a fact? Unanswerable.

Even before this, the Introduction had staked out its ground, stating that "Our brains are built for maps," an assertion even more debatable than the unrivaled artistry claim. Fortunately, this sort of grandiloquence occurs infrequently_and I point it out because it is so surprising.

Any map geek might easily finish All Over the Map disappointed that some or other pet map of their own did not make it into its pages, and scratching their head about some of the ones that did. Consider, though: if you already know about the map and its story, does it really need to be included? I felt that some of the topical asides may not age gracefully, and I would also have preferred less skew toward present-day maps. In particular, the "Landscapes" chapter would have benefited from some older stories. The earliest concerns Frederick Law Olmsted's 1871 design for Brooklyn's Prospect Park (137-137) - I should think there would be several even older candidates. Are there better stories in the past? Perhaps, or perhaps the objection is a bit petty. The stories that are included live up to their promise, and the book does, after all, need to sell.

The section entitled "Flattening the World"-in the "Worlds" chapter-is a reasonable discussion of the topic, but it has a problem or two. For one thing, it is not surprising that the authors give an ad hoc list of distortion types: "Projections can distort five aspects of geography: area, shape, distance, angle, and direction" (265); indeed, variants of this list crop up throughout the general-audience cartographic literature-much of it written by cartographers. The problem is that this ad hoc list tends to muddle rather than clarify the issue. The reality is that there are only three independent metrics-area, angle, and proximity - and that, depending on how these three are handled by the projection, no end of other geographical metrics can be distorted. Proximity is especially notable as the metric that somehow never makes it onto these lists-even though every map is interrupted, some of them repeatedly. For example, the Fuller Dymaxion and Cahill Butterfly, both illustrated right there on the next page, are both easily recognized by their interruptions. Also on page 265 , in both the text body and in a caption, there is a description of the Peters projection that tells us that "the continents are stretched vertically near the equator"which is correct- "and compressed horizontally near the poles"-which is not correct, and quite obviously so. I'm also disgruntled about the way the Peters hogs the stage as the only equal-area projection mentioned-precisely as Arno Peters schemed, and despite a long and storied history of equal-area maps. But, these noted exceptions aside - and I'm really not sure I've ever read a popular account of map projections that I did not find unnecessarily misleading - this chapter is, as I mentioned above, otherwise reasonable.

Stepping back to assess my entire tour through All Over the Map, I found the stories informative and enjoyable, and their selection sensible. The authors' choice to home in on lesser-known tales even for famous mapmakerssuch as Olmstead's Prospect Park instead of his Central Park-meant that most of what I read was new to me. The selection prioritized interesting stories over pretty maps, and is a policy I thoroughly endorse. Don't get me wrong; 
you will feast on plenty of fine and beautiful and striking cartography-just don't suppose that pretty maps are the whole meal. Overall, I found that the prose was engaging, and that the journalistic bent offered an uncommon perspective. I daresay that the selection and presentation benefited by having originated outside academic circles. This is commendable work.
Does this odyssey all over the map add up to anything? It might if you let it. It definitely won't if you don't. Even if you never read the entire book, there is plenty of satisfaction and knowledge to be had by reading individual stories scattershot. The more of these compelling stories you read, though, the more profoundly and poignantly you will apprehend the meanings behind the singularly human impulse to map our knowledge, our experiences, and our yearnings. 